\title{
Practices of community pharmacists toward antimicrobials use and the application of antimicrobial stewardship
}

\author{
Doaa Saleh ${ }^{1}$, Rana Abu Farha ${ }^{1 *}$, Mohammed Zawiah ${ }^{2,3}$ \\ ${ }^{1}$ Department of Clinical Pharmacy and Therapeutics, Faculty of Pharmacy, Applied Science Private University, Amman, Jordan. \\ ${ }^{2}$ Department of Clinical Pharmacy, School of Pharmaceutical Science, University Sains Malaysia, Penang, Malaysia. \\ ${ }^{3}$ Department of Pharmacy Practice, College of Clinical Pharmacy, University of Al-Hodeida, Al Hodeida, Yemen.
}

\begin{tabular}{l}
\hline ARTICLE INFO \\
\hline Received on: $30 / 08 / 2021$ \\
Accepted on: $12 / 11 / 2021$ \\
Available Online: 05/03/2022 \\
\hline Key words: \\
Antimicrobial stewardship, \\
practice, pharmacists, \\
community pharmacy, Jordan.
\end{tabular}

\section{INTRODUCTION}

Antibiotic resistance is currently considered one of the most serious public health issues that increases morbidity and mortality rates and imposes a huge burden on healthcare systems around the world (Abushaheen et al, 2020; Cassini et al, 2019). Inappropriate antibiotic utilization is a well-recognized contributor to developing resistance, which may be aided by greater antimicrobial availability in the community setting (WHO, 2020). Over the last two decades, health authorities, particularly the World Health Organization, have advised member governments to develop suitable policies and allocate resources to combat antibiotic resistance (WHO, 2020). Accordingly, several antimicrobial stewardship (AMS) measures have been proposed and implemented to fight the problem (Rusic et al, 2021). AMS includes all regulatory, educational, operational,

\footnotetext{
*Corresponding Author

Rana Abu Farha, Department of Clinical Pharmacy and Therapeutics, Faculty of Pharmacy, Applied Science Private University, Amman, Jordan. E-mail:r_abufarha@asu.edu.jo
}

and institutional processes and actions undertaken to ensure the judicious use of antibiotics (Chung et al, 2013).

However, preservation of such public health issues requires every healthcare provider to be involved in efforts to promote prudent use of antibiotics and reduce the emergence of antimicrobial resistance. Pharmacists can play an important role in AMS activities in community settings for several reasons. To begin with, pharmacists are providing value-added services as healthcare providers and not solely as medication dispensers (Bishop et al, 2019; Winslade and Tamblyn, 2017). Furthermore, community pharmacists are among the most accessible healthcare professionals that have a unique position within the community, allowing them to engage in addressing health concerns at the community level (Kenealy and Arroll, 2013). Moreover, community pharmacists are unique members of the healthcare team that can liaise readily between patients and physicians, which allows for opportunities to operationalize any framework in the AMS work (Essack et al, 2018). Thus, expansion of AMS interventions to all hospital and eventually community practices will ultimately result in proper antibiotic use and, as a result, reduce antibiotic resistance in the general population (Buckel et al, 2018). 
Nevertheless, in developing countries, information on the implementation of stewardship strategies at the community level is scarce, and the involvement of community pharmacists in such activities is less well established (Essack et al, 2018; Sakeena et al, 2018; Saleh et al, 2021). In Jordan, the application of AMS is a major public health concern. There are regulations related to antibiotics that have been enforced by regulatory authorities to improve current practices related to antibiotic consumption (JFDA, 2016; WHO, 2018). In the community practice, a recent study found that the perception of community pharmacists regarding the AMS program was positive because they believed that pharmacists are experts in antimicrobial drugs. However, certain barriers such as organizational, resources, and personal obstacles were highlighted (Saleh et al, 2021). No study has been undertaken to evaluate the practice of community pharmacy staff regarding antimicrobial use and AMS strategies in Jordan. Therefore, this cross-sectional study was designed to investigate the current practices of community pharmacists in dealing with antimicrobials and AMS in Jordan and to evaluate factors affecting their application of AMS.

\section{METHODS}

\section{Study design, participants, and settings}

An online-based cross-sectional study was conducted with community pharmacies in Jordan over a period of 2 months, from August to September 2020, using a structured questionnaire. Pharmacists who had registered licenses to practice the pharmacy profession at the Jordan Pharmaceutical Association were invited to participate. The questionnaire was distributed electronically via social media platforms in Jordan, including WhatsApp and Facebook. Those willing to partake could open a link to initially view the study aim, the potential benefits of the survey, confidentiality of data, and the voluntariness of participation. After that, they were asked to provide their electronic consent before proceeding to the study.

\section{Sample size calculation}

Based on Tabachnick and Fidell's (2006) recommendation for sample size calculation in multiple linear regression analyses used to assess factors affecting pharmacists' AMS application score, 20 subjects per predictor were recommended. Since 7 predictors were considered, a minimum sample size of 140 was appropriately representative.

\section{Questionnaire development}

An extensive literature review of relevant studies was used to construct the study instrument (Erku, 2016; Khan et al, 2016; Sarwar et al, 2018). The original draft of the developed instrument was evaluated for face validity by four independent researchers, and modifications were made accordingly based on the feedback and comments provided. Then, the survey was tested with a pilot study on a group of pharmacists to assure the clarity and comprehensibility of the items. The responses from these samples were excluded from the final analysis. Cronbach's alpha test was used to test the internal reliability, which yielded a 0.864 ; thus, the current scale has reliable and excellent internal consistency. The final version of the questionnaire included 20 items, and it was mainly divided into 3 main themes. The first theme (Q1-Q7) focused on the participants' sociodemographic information, including age, gender, level of education, experience, workplace, the daily number of patients served, and if they attended any previous ASM workshop. The second theme (Q8Q16) focused on evaluating community pharmacists' practice in applying ASM standards, while the third part (Q17-Q20) assessed pharmacists' participation in sharing awareness about the proper use of antimicrobials. In the second and third themes, the scores were calculated based on a 5-point Likert scale (5: always, 4: often, 3: sometimes, 2: rarely, and 1: never). AMS application scores ranged from 9 to 45 , in which gaining a higher score indicates a better application of AMS strategies and vice versa.

\section{Ethical consideration}

The ethical approval was obtained from the Institutional Review Board at the Applied Science Private University (approval number 2020-PHA-20). The survey complied with the ethical standards outlined in the World Medical Association Declaration of Helsinki guideline (WMA, 2014).

\section{Statistical analysis}

Statistical Package for the Social Sciences (SPSS) version 22 (SPSS Inc., Chicago, IL) was used to perform both descriptive and inferential analysis. Continuous variables were presented as median interquartile range (IQR), while categorical variables were reported using frequencies and percentages. Univariate followed by multivariate linear regression was applied to determine the factors that affect participants' AMS application score. Variables that were found to be significant on a single predictor level ( $p$-value $<0.25)$ using univariate linear regression analysis were entered into the multivariate linear regression model. Variables were selected after checking their independence, where the Pearson correlation coefficient $(r)$ less than 0.9 indicated the absence of multicollinearity between the independent variables in regression analysis.

\section{RESULTS}

During the study period, 200 community pharmacists filled out the study questionnaire, with around two-thirds of them being females $(n=129,64.5 \%)$. The median age of the participated pharmacists was $30(\mathrm{IQR}=11)$, and most of them had a BPharm/PharmD $(n=160,80.0 \%)$. More than three-quarters of the pharmacists $(n=173,76.5 \%)$ reported to work in independent community pharmacies; also, less than half of them $(n=90$, $45.0 \%)$ stated that they serve more the 50 patients/day. Finally, only 38 pharmacists' $(19.0 \%)$ stated that they did not attend any course/workshop regarding the AMS. For more details, refer to Table 1.

All the participants responded to nine self-reported statements regarding the practice of community pharmacists in applying AMS (Table 2). Accordingly, around three-quarters of the respondents $(n=154,77.0 \%)$ always/often dispense antimicrobials with prescriptions, which have all clinical information. Moreover, $73.5 \%$ of them always/often evaluate the prescribed antimicrobials if they follow the guidelines.

Additionally, most of the participants reported to always/often ask about any possible drug interaction, an adverse 
Table 1. Demographic characteristics of the study sample at baseline $(n=200)$.

\begin{tabular}{|c|c|c|}
\hline Parameter & Median (IQR) & $n(\%)$ \\
\hline Age (years) & $30.0(11.0)$ & \\
\hline $\begin{array}{l}\text { Gender } \\
\text { Female } \\
\text { Male }\end{array}$ & & $\begin{array}{c}129(64.5 \%) \\
71(35.5 \%)\end{array}$ \\
\hline $\begin{array}{l}\text { Educational level } \\
\text { BPharm/Pharm D } \\
\text { MSc/PhD }\end{array}$ & & $\begin{array}{c}160(80.0 \%) \\
40(20.0 \%)\end{array}$ \\
\hline Community practice experience (years) & $5.0(8.0)$ & \\
\hline $\begin{array}{l}\text { Site of work } \\
\text { Independent community pharmacy } \\
\text { Chain community pharmacy }\end{array}$ & & $\begin{array}{c}153(76.5 \%) \\
47(23.5 \%)\end{array}$ \\
\hline $\begin{array}{l}\text { Number of patients you provide a service to them/day } \\
<50 \\
\geq 50\end{array}$ & & $\begin{array}{c}110(55.0 \%) \\
90(45.0 \%)\end{array}$ \\
\hline $\begin{array}{l}\text { Have you ever attended a course/workshop about AMS programs? } \\
\text { No } \\
\text { Yes }\end{array}$ & & $\begin{array}{c}38(19.0 \%) \\
162(81.0 \%)\end{array}$ \\
\hline $\mathrm{R}$ : interquartile range. & & \\
\hline
\end{tabular}

Table 2. Assessment of community pharmacists' practice regarding the application of AMS standards $(n=200)$.

\begin{tabular}{|c|c|c|c|c|c|}
\hline Statements & $\begin{array}{l}\text { Always } \\
n(\%)\end{array}$ & $\begin{array}{l}\text { Often } \\
n(\%)\end{array}$ & $\begin{array}{l}\text { Sometimes } \\
\quad n(\%)\end{array}$ & $\begin{array}{l}\text { Rarely } \\
n(\%)\end{array}$ & $\begin{array}{l}\text { Never } \\
n(\%)\end{array}$ \\
\hline $\begin{array}{l}\text { I dispense antimicrobials with prescriptions which } \\
\text { have all clinical information }\end{array}$ & $87(43.5 \%)$ & $67(33.5 \%)$ & $30(15.0 \%)$ & $13(6.5 \%)$ & $3(1.5 \%)$ \\
\hline $\begin{array}{l}\text { I change the prescribed antimicrobial if I am } \\
\text { unsure about the appropriateness of the prescribed } \\
\text { antimicrobial }\end{array}$ & $26(13.0 \%)$ & $52(26.0 \%)$ & $54(27.0 \%)$ & $49(24.5 \%)$ & $19(9.5 \%)$ \\
\hline $\begin{array}{l}\text { I evaluate the prescribed antimicrobials if the } \\
\text { prescribed antimicrobials follow the guidelines }\end{array}$ & $69(34.5 \%)$ & $78(39.0 \%)$ & $37(18.05 \%)$ & $11(5.5 \%)$ & $5(2.5 \%)$ \\
\hline $\begin{array}{l}\text { I take into account any possible drug interaction, an } \\
\text { adverse effect before dispensing antimicrobial }\end{array}$ & $94(47.0 \%)$ & $66(33.0 \%)$ & $37(18.5 \%)$ & $2(1.0 \%)$ & $1(0.5 \%)$ \\
\hline $\begin{array}{l}\text { I ask patients about history of allergy before I dispense } \\
\text { antimicrobials }\end{array}$ & $107(53.5 \%)$ & $52(26.0 \%)$ & $33(16.5 \%)$ & $7(3.5 \%)$ & $1(0.5 \%)$ \\
\hline $\begin{array}{l}\text { I change the prescribed antimicrobial if the patient has } \\
\text { allergies to the prescribed antimicrobial }\end{array}$ & $106(53.0 \%)$ & $52(26.0 \%)$ & $30(15.0 \%)$ & $7(3.5 \%)$ & $5(2.5 \%)$ \\
\hline $\begin{array}{l}\text { I refer the patient to physicians in the presence of } \\
\text { symptom of infection }\end{array}$ & $63(31.5 \%)$ & $75(37.5 \%)$ & $56(28.0 \%)$ & $4(2.0 \%)$ & $2(1.0 \%)$ \\
\hline $\begin{array}{l}\text { I communicate with prescriber if I cannot read the } \\
\text { prescription }\end{array}$ & $116(58.0 \%)$ & $54(27.0 \%)$ & $26(13.0 \%)$ & $3(1.5 \%)$ & $3(1.5 \%)$ \\
\hline $\begin{array}{l}\text { I contact the prescriber if the antimicrobial dose/ } \\
\text { frequency is too high or too low }\end{array}$ & $86(43.0 \%)$ & $69(34.5 \%)$ & $35(17.5 \%)$ & $8(4.0 \%)$ & $2(1.0 \%)$ \\
\hline
\end{tabular}

effect before dispensing antimicrobial ( $n=160,80.0 \%$ ), ask patients about history of allergy before dispensing antimicrobials ( $n=159,79.5 \%$ ), and change the prescribed antimicrobial if the patient has allergies to them $(n=158,79.0 \%)$. Besides, most of the respondents $(n=170,85.0 \%)$ always/often communicate with prescribers if they have difficulty reading the prescription.

Pharmacists' participation in spreading awareness about antimicrobials' proper use is presented in Figure 1. It was noticed that $67.0 \%$ of the participants $(n=135)$ always/often participate in campaigns related to antimicrobial awareness. Also, most pharmacists always/often educate patients about the expected side effects $(n=154,77.0 \%)$ and what they should do if they experience any side effects $(n=149,74.5 \%)$. Also, educating the patients about the importance of completing the antimicrobial course in controlling microbial resistance was always/often done by $84.0 \%(n=168)$ of the participants.

Finally, linear regression analysis (Table 3) revealed that pharmacists with postgraduate education had a lower AMS application score compared to those with undergraduate educational degrees $(p=0.031)$. None of the other sociodemographic factors were found to have a significant effect on pharmacists' AMS application scores $(p>0.05)$. 


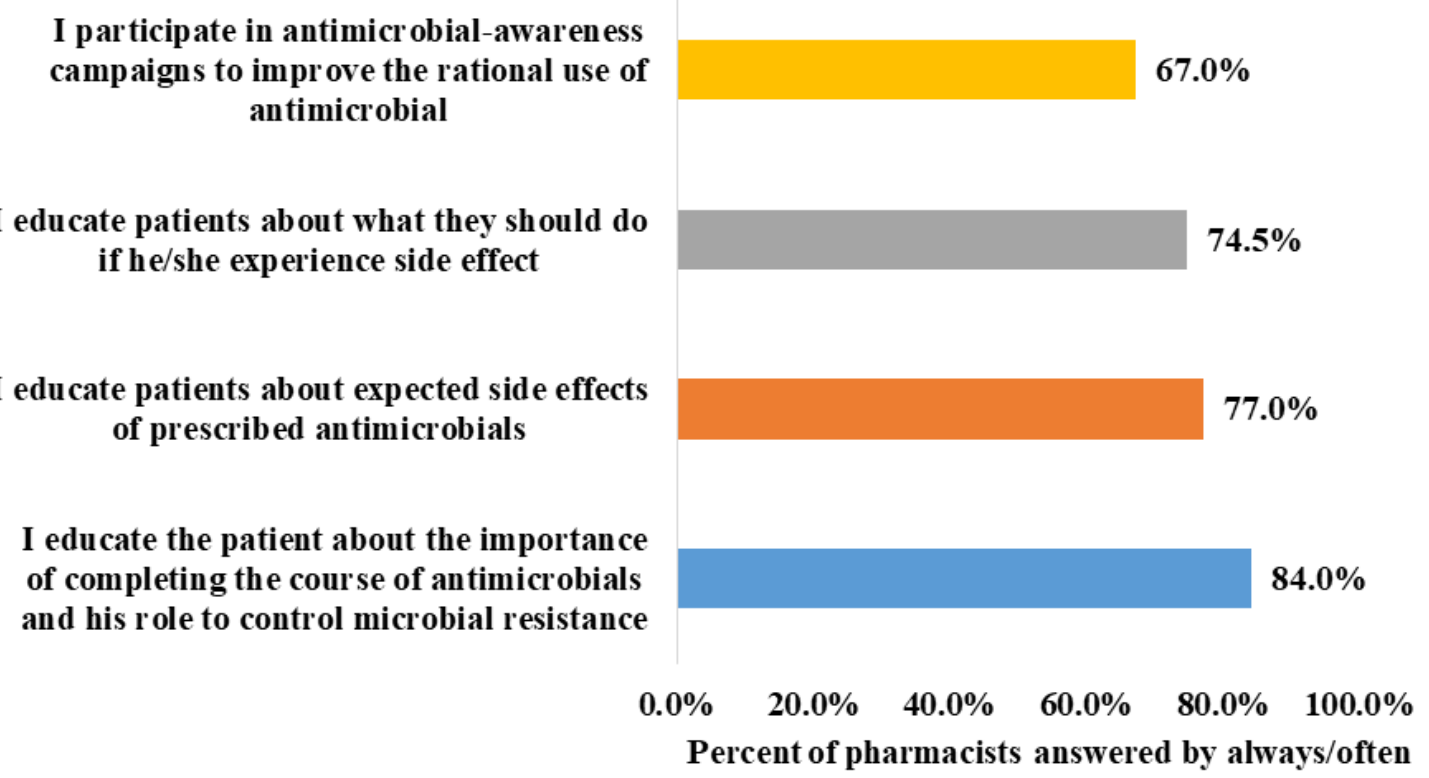

Figure 1. Pharmacists' participation in spreading awareness about antimicrobials' proper use $(n=200)$.

Table 3. Regression analysis for factors affecting AMS application scores among study sample $(n=200)$.

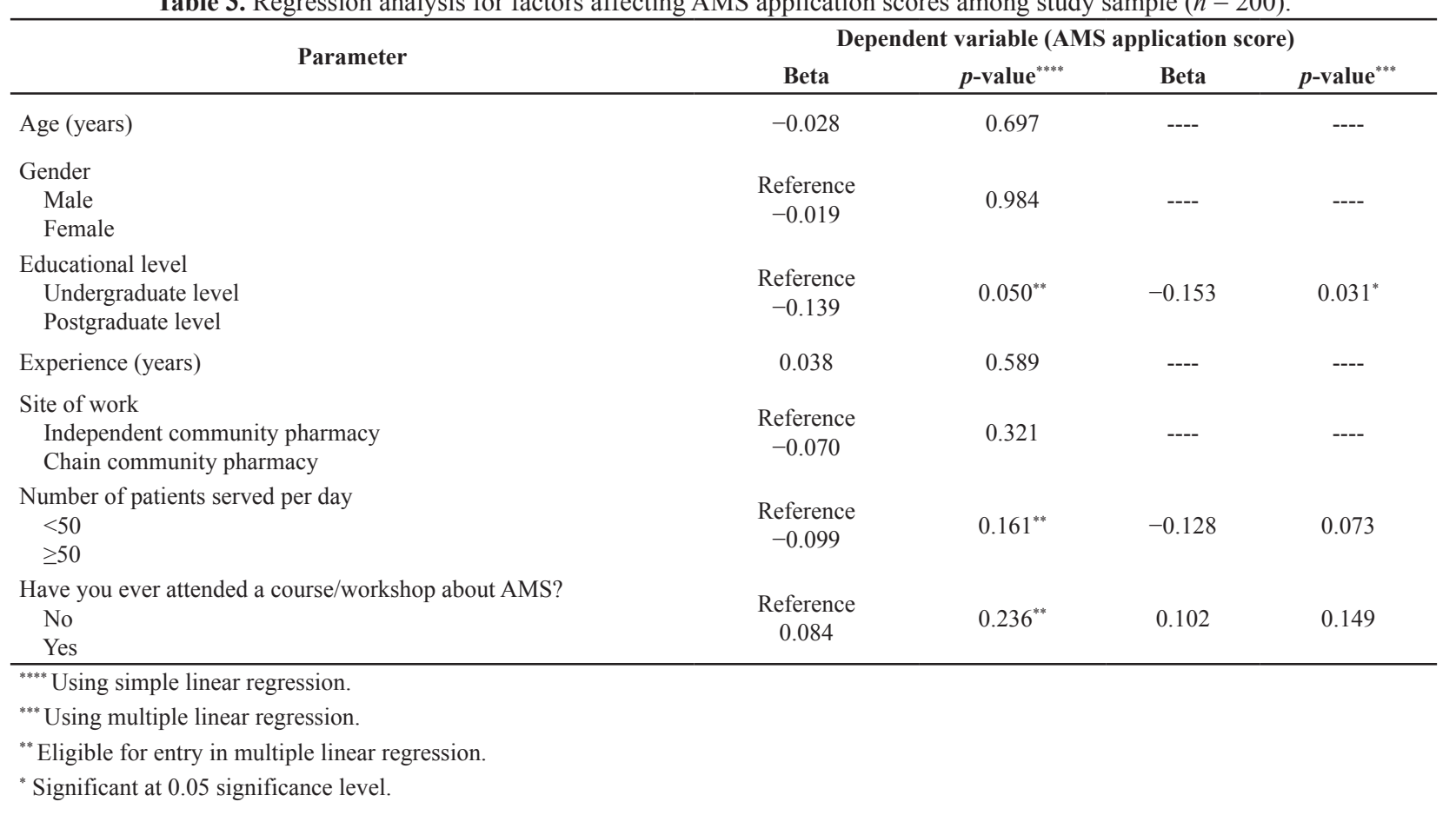

\section{DISCUSSION}

Wise consumption of antibiotics is considered a fundamental approach to maintain the efficacy of antimicrobials against infectious disease and to control the emergence of resistance strain (Parsonage et al, 2017). Pharmacists play a crucial role in infectious control programs within the healthcare settings, and they have essential roles in the implementation of the AMS program (Essack et al, 2018). Moreover, many studies emphasize the expanding role of community pharmacists in mediating the rational use of antimicrobials (Broom et al, 2015; Drekonja et al, 2015; Sarwar et al, 2018). Till now, no previous study has evaluated the current practice of community pharmacy staff regarding antimicrobial use and AMS strategies in Jordan. Therefore, this study provides an important vision into the current practice of community pharmacists toward AMS at the community pharmacy setting in Jordan. 
In Jordan, AMS programs are not well established, but fortunately, the community pharmacists reported a positive practice toward their role in AMS application. The majority of respondents claimed that they dispense the prescription with all the clinical information on it. Also, they evaluate the appropriateness of the prescribed antimicrobials. A similar finding was reported by a study conducted in Ethiopia (Erku, 2016) and another conducted in Pakistan (Sarwar et al, 2018), where most of the pharmacists dispensed antimicrobials properly only when all required needed information was available within the prescription.

Proper communication with patients regarding their medications plays a vital role in achieving the optimal outcomes from their medications. Thus, it is important for community pharmacists to take an active role in communicating with each patient (Rogers and King, 2012). The majority of our participants reported to ask about any drug interaction, allergies, and adverse reactions before dispensing antimicrobial agents. Such practice will ensure delivering the most effective and safest possible antimicrobials to patients. Similar results were reported in a study conducted in Tasmania, where most of the pharmacists showed an active role in identifying any experienced adverse effects by patients, any possible drug interactions, and any allergies. But unfortunately, less than half communicate with physicians if they identify any error in antimicrobial selection (Rizvi et al, 2018). Also, only around half of the community pharmacists claimed that they always change the prescribed antimicrobials if the patient has allergies to them. It could be because pharmacists do not have the authority to modify patients' prescriptions since physicians are reluctant to accept pharmacists' recommendations, even when the recommendations are evidence-based or of major concern (Elayeh et al, 2017). This issue can be resolved by establishing workshops that focus on the implementation of interprofessional collaborations, which is considered a key strategy in healthcare reforming.

Providing optimal patient care requires pharmacists to have proper communication with all other healthcare providers, including physicians (Rogers and King, 2012). The collaboration of community pharmacists with physicians is considered a keystone to control and reduce antimicrobial resistance. Our study revealed that the majority of the recruited pharmacists communicate with prescribers if they feel that there is something wrong with the antimicrobial prescription. This practice was also reported by Malaysian community pharmacists who stated that they often communicate with prescribers overusing antibiotics (Khan et al, 2016). Furthermore, another study conducted in Tasmania stated that most community pharmacists believed that the collaboration between pharmacists and other healthcare settings is needed to improve antimicrobial prescription (Rizvi et al, 2018).

Our study revealed that our pharmacists have a desire to spread awareness toward AMS. More than half of the participants tend to participate in campaigns related to AMS, compared to $30 \%$ of the Malaysian pharmacists who stated that they occasionally participate in a campaign associated with AMS. At the same time, these findings correlate with studies that show that most pharmacists took part in stewardship awareness (Cotta et al, 2014; Erku, 2016). As community pharmacists are considered the most accessible healthcare providers (Tsuyuki et al, 2018), pharmacists should be encouraged to participate in AMS awareness initiatives to be able to improve public awareness about antimicrobials' rational use.

The result of this study found that the qualification of the participants is considered a significant determinant factor toward AMS application. Surprisingly, pharmacists with postgraduate education had a lower AMS application score compared to those with an undergraduate educational degree. Our finding was opposite to the Malaysian study, which revealed that pharmacists having postgraduate degrees were more engaged in AMS activities than their undergraduate colleagues (Khan et al, 2016).

Among the main limitation of this study is that the pharmacists were invited to participate through social media, which introduced selection bias; as some proportion of the community pharmacists do not have active social media profiles, this may limit the generalizability of results to the general population. Also, this study relied on pharmacists' self-assessment to their practice, which could overestimate their actual adherence to the rational prescription of antimicrobials. Furthermore, future research could explore facilitators and barriers to the implementation of interprofessional collaborations between community pharmacists and other healthcare providers.

\section{CONCLUSION}

Community pharmacists show a positive practice toward AMS. Still, some points need to be issued, such as improving the collaboration between community pharmacists with patients and other healthcare settings. Pharmacists should be encouraged to participate in AMS awareness initiatives to be able to improve public awareness about antimicrobials' rational use.

\section{FUNDING}

There is no funding to report.

\section{CONFLICTS OF INTEREST}

The authors report no financial or any other conflicts of interest in this work.

\section{ETHICAL APPROVALS}

The ethical approval was obtained from the Institutional Review Board at the Applied Science Private University (approval number 2020-PHA-20).

\section{DATA AVAILABILITY}

The corresponding author is responsible to provide the related study data.

\section{PUBLISHER'S NOTE}

This journal remains neutral with regard to jurisdictional claims in published institutional affiliation.

\section{AUTHOR CONTRIBUTIONS}

Doaa Saleh: study design, data collection, data analysis, and manuscript writing.

Rana Abu Farha: study design, data collection, data analysis, and manuscript writing.

Mohammed Zawiah: study design, data analysis, and manuscript writing. 


\section{REFERENCES}

Abushaheen MA, Fatani AJ, Alosaimi M, Mansy W, George M, Acharya S, Rathod S, Divakar DD, Jhugroo C, Vellappally S. Antimicrobial resistance, mechanisms and its clinical significance. Dis Mon, 2020; 66(6): 100971.

Bishop C, Yacoob Z, Knobloch MJ, Safdar N. Community pharmacy interventions to improve antibiotic stewardship and implications for pharmacy education: a narrative overview. Res Social Adm Pharm, 2019; 15(6):627-31.

Broom A, Broom J, Kirby E, Plage S, Adams J. What role do pharmacists play in mediating antibiotic use in hospitals? A qualitative study. BMJ Open, 2015; 5:e08326.

Buckel WR, Veillette JJ, Vento TJ, Stenehjem E. Antimicrobial stewardship in community hospitals. Med Clin, 2018; 102(5):913-28.

Cassini A, Högberg LD, Plachouras D, Quattrocchi A, Hoxha A, Simonsen GS, Colomb-Cotinat M, Kretzschmar ME, Devleesschauwer B, Cecchini M, Ouakrim DA, Oliveira TC, Struelens MJ, Suetens C, Monnet DL. Attributable deaths and disability-adjusted life-years caused by infections with antibiotic-resistant bacteria in the EU and the European Economic Area in 2015: a population-level modelling analysis. Lancet Infect Dis, 2019; 19(1):56-66.

Chung GW, Wu JE, Yeo CL, Chan D, Hsu LY. Antimicrobial stewardship: a review of prospective audit and feedback systems and an objective evaluation of outcomes. Virulence, 2013; 4(2):151-7.

Cotta MO, Robertson MS, Tacey M, Marshall C, Thursky KA, Liew D, Buising KL. Attitudes towards antimicrobial stewardship: results from a large private hospital in Australia. J Hosp Infect, 2014; 19(3):89-94.

Drekonja DM, Filice GA, Greer N, Olson A, MacDonald R, Rutks I, Wilt T. Antimicrobial stewardship in outpatient settings: a systematic review. Infect Control Hosp Epidemiol, 2015; 36(2):142-52.

Elayeh E, Akour A, Almadaeen S, AlQhewii T, Basheti IA. Practice of pharmaceutical care in community pharmacies in Jordan. Trop J Pharm Res, 2017; 16(2):463-70.

Erku DA. Antimicrobial stewardship: a cross-sectional survey assessing the perceptions and practices of community pharmacists in Ethiopia. Interdiscip Perspect Infect Dis, 2016; 2016:1-6.

Essack S, Bell J, Shephard A. Community pharmacists - leaders for antibiotic stewardship in respiratory tract infection. J Clin Pharm Ther, 2018; 43(2):302-7.

JFDA. Jordan Food and Drug Administration. Pharmacovigilance of medications. Jordan Food and Drug Administration, Amman, Jordan, 2016 (Accessed 12 October 2020).

Kenealy T, Arroll B. Antibiotics for the common cold and acute purulent rhinitis. Cochrane Database Syst Rev, 2013(6):CD000247.

Khan MU, Hassali MAA, Ahmad A, Elkalmi RM, Zaidi STR, Dhingra S. Perceptions and practices of community pharmacists towards antimicrobial stewardship in the State of Selangor, Malaysia. PLoS One, 2016; 11(2):e0149623.

Parsonage B, Hagglund PK, Keogh L, Wheelhouse N, Brown RE, Dancer SJ. Control of antimicrobial resistance requires an ethical approach. Front Microbiol, 2017; 8:2124.
Rizvi T, Thompson A, Williams M, Zaidi STR. Perceptions and current practices of community pharmacists regarding antimicrobial stewardship in Tasmania. Int J Clin Pharm, 2018; 40(5):1380-7.

Rogers ER, King SR. The influence of a patient-counseling course on the communication apprehension, outcome expectations, and self-efficacy of first-year pharmacy students. Am J Pharm Educ, 2012; 76(8):152.

Rusic D, Bukić J, Seselja Perisin A, Leskur D, Modun D, Petric A, Vilovic M, Bozic J. Are we making the most of community pharmacies? Implementation of antimicrobial stewardship measures in community pharmacies: a narrative review. Antibiotics, 2021; 10(1):63.

Sakeena M, Bennett AA, McLachlan AJ. Non-prescription sales of antimicrobial agents at community pharmacies in developing countries: a systematic review. Int J Antimicrob Agents, 2018; 52(6):771-82.

Saleh D, Abu-Farha R, Mukattash TL, Barakat M, Alefishat E. Views of community pharmacists on antimicrobial resistance and antimicrobial stewardship in Jordan: a qualitative study. Antibiotics, 2021; 10(4):384.

Sarwar MR, Saqib A, Iftikhar S, Sadiq T. Knowledge of community pharmacists about antibiotics, and their perceptions and practices regarding antimicrobial stewardship: a cross-sectional study in Punjab, Pakistan. Infect Drug Resist, 2018; 11:133.

Tabachnick BG, Fidell LS. Using multivariate statistics. 5th edition, Allyn and Bacon/Pearson Education, New York, NY, 2006.

Tsuyuki RT, Beahm NP, Okada H, Al Hamarneh YN. Pharmacists as accessible primary health care providers: review of the evidence. Can Pharm J, 2018; 151(1):4-5.

WHO. WHO provides support to the Jordanian Ministry of Health in developing a national antimicrobial resistance surveillance system. Geneva, Switzerland, WHO, 2018. (Accessed 12 October 2020).

WHO. Antimicrobial resistance. Geneva, Switzerland, WHO, 2020.

Winslade N, Tamblyn R. Determinants of community pharmacists' quality of care: a population-based cohort study using pharmacy administrative claims data. BMJ Open, 2017; 7(9):e015877.

WMA. World Medical Association Declaration of Helsinki ethical principles for medical research involving human subjects. J Am Coll Dent, 2014; 81(3):14.

How to cite this article:

Saleh D, Farha RA, Zawiah M. Practices of community pharmacists toward antimicrobials use and the application of antimicrobial stewardship. J Appl Pharm Sci, 2022; 12(03):218-223. 